Article

\title{
Study of a Hydrogen Inhibition Method with Sodium Tungstate for Wet Aluminum Dust Removal Systems
}

\author{
Bohan Zhang ${ }^{1,2}$, Kaili Xu ${ }^{1,2, *}$, Xin Zheng ${ }^{1,2}$, Xiwen Yao ${ }^{1,2, *}$, Yantong Wang ${ }^{3}$ and Ji Ge ${ }^{1,2}$ \\ 1 Key Laboratory of Ministry of Education on Safe Mining of Deep Metal Mines, Northeastern University, \\ Shenyang 110819, China; zhaopengyuani@163.com (B.Z.); zhengxin@mail.neu.edu.cn (X.Z.); \\ geji2016@yeah.net (J.G.) \\ 2 College of Resources and Civil Engineering, Northeastern University, Shenyang 110819, China \\ 3 Sinochem Environment Holdings Co. Ltd., Beijing 100000, China; wangyantong@sinochem.com \\ * Correspondence: xukaili@mail.neu.edu.cn (K.X.); yaoxiwen@mail.neu.edu.cn (X.Y.)
}

Received: 5 April 2020; Accepted: 26 April 2020; Published: 28 April 2020

\begin{abstract}
Hydrogen, which can be produced due to the accumulation of aluminum dust that reacts with water in wet dust removal systems, is a fire and explosion hazard. To reduce hydrogen production, sodium tungstate is used in hydrogen inhibition experiments to inhibit the reaction between aluminum dust and water. The purity of the aluminum powder was $95.15 \%$, analyzed with X-ray fluorescence spectrometry (XRF). Each of the hydrogen inhibition experiments lasted for $12 \mathrm{~h}$. In addition, scanning electron microscopy (SEM), energy dispersive spectroscopy (EDS), $\mathrm{X}$-ray diffraction (XRD) and X-ray photoelectron spectroscopy (XPS) were used to characterize the surface morphology and composition of particles before and after the experiments. There was nearly no hydrogen produced when the concentration of the sodium tungstate solution reached $100 \mathrm{~g} / \mathrm{L}$. The results show that a protective coating containing $\mathrm{W}$ element was formed on the surface of the aluminum particles after the reaction with sodium tungstate, and the coating prevented the aluminum particles from contacting with water.
\end{abstract}

Keywords: sodium tungstate; wet dust removal system; aluminum dust; coating; hydrogen inhibition

\section{Introduction}

Aluminum is widely used in industry, such as in electronic products, automobile manufacturing and architectural decoration materials. In the workshop, the surface of the finished product needs to be polished; thus, many high temperature aluminum powders are produced. These aluminum powders needs to be handled by a wet dust removal system, where the aluminum powder contacts with water to produce up to $3.7-4.8 \mathrm{wt} \%$ hydrogen, and the reaction byproducts are chemically neutral. If the volume concentration of hydrogen in air is between $4.0 \%$ and $75.6 \%$, then the hydrogen will explode [1].

In 2014, a serious combustible dust explosion occurred in Kunshan City (China). The explosion was caused from the accumulation of aluminum dust in the workshop upon which it formed a dust cloud due to the failure of the precipitator; the aluminum powder is damp and oxidatively exothermic, and reached the ignition temperature of the dust cloud, and these characteristics eventually caused a chain explosion [2]. In addition, a hydrogen accumulation explosion resulting in three deaths occurred at Hoeganaes Co., which is a company that produces atomized steel and iron powders in the USA [3].

Because of the abovementioned problems, Myers [4] discussed the use of an inerting method to reduce the risk of dust explosions of residues from aluminum polishing operations. However, less attention has been paid to solving the problem of aluminum powder generating hydrogen in wet 
scrubbers. We mainly consider on how to form the protective coatings on the aluminum particles in water to eliminate hydrogen.

In experiments by Jensen [5], a coating of doped tungstate on Al flakes had a deficiency in the anode transfer corrosion potential of approximately $300 \mathrm{mV}$ compared to when the coating used $\mathrm{Al}$ flakes alone. The potential difference is released as the results of the dopant ions of the anode inhibitor demonstrate that tungstate can slow the rate of metal dissolution. An oxide layer is quickly formed on the surface of the aluminum dust if exposed to air [6].

Tseng et al. [7] believed that tungstate ions have a dual role in metal corrosion. When the tungstate concentration is low, it acts as a cathode depolarizer to accelerate the corrosion of the metal, and when the tungstate concentration is high, it is advantageous to form the passivation coating. For the inhibition mechanism of tungstate, if the tungstate is considered to be the precipitation adsorption, the adsorption theory holds that the adsorption of the corrosion inhibitor on the metal surface limits the free flow of electrons and reduces the chemical activity [8].

According to previous research [8], tungstate is an adsorption-inhibiting inhibitor. Because its oxidizing ability is lower than that of chromate, it can only be inhibited if there is dissolved oxygen in the water. As a green inhibitor, sodium tungstate combined with other organic substances is almost nontoxic and harmless to the environment and people [9,10].

Through experiments, Yao [11] indicated that the adsorption of sodium tungstate molecules on the surface of magnesium alloy is a spontaneous process. Here, $\mathrm{WO}_{4}{ }^{2-}$ is an effective inhibitory component that participates in the formation of the surface coating of the magnesium alloy sample, preventing the reaction of the corrosive medium and the matrix. This standard adsorption heat is negative, indicating that the adsorption process of sodium tungstate is an exothermic process. In addition, the absolute value of the standard adsorption heat is between the physical adsorption heat value and the chemisorption heat value, indicating that the adsorption process of sodium tungstate may occur at the same time as physical adsorption and chemical adsorption. Li et al. [12] believe that the inhibition rate of tungstate is not high when used alone, and a relatively large amount is also used, generally $10^{-3} \mathrm{~mol} / \mathrm{L}$. However, tungstate has the advantage that strong oxidants do not have and can be used in combination with organic inhibitors or other water treatment agents.

Wang et al. [13-15] proposed the use of chromate and dichromate to inhibit the reactions between aluminum and water in wet dust removal systems. Xu et al. [16] preferred to study $\mathrm{CeCl}_{3}$ to inhibit hydrogen production in wet dust removal systems. However, the carcinogenicity of chromate and dichromate and of $\mathrm{CeCl}_{3}$ have caused poisoning incidents during their popularization in industry. Zheng et al. $[17,18]$ researched sodium silicate and L-phenylalanine to inhibit the reactions between aluminum and water from the perspective of employing environmentally friendly inhibitors. Nevertheless, there is a hydrolysis reaction of sodium silicate, which will attenuate the inhibitory effect as the time of application in water increases. The reaction of L-phenylalanine with aluminum powder produces a large amount of byproducts that are difficult to clean, causing cleaning troubles of the inside walls of the wet scrubber in industry.

Based on the above, sodium tungstate is considered to be the inhibitor to reduce or even eliminate hydrogen production in wet dust removal systems.

The objectives of this work are as follows:

- Study the process and mechanism of the reaction of aluminum powder with water.

- The main objective of the study is determining the optimum inhibitory concentration of the sodium tungstate solution to provide a basis for future applications in wet dust removal systems.

- Analyze the composition of the protective coatings after the reaction. 


\section{Experimental}

\subsection{Experimental Equipments and Materials}

The experimental aluminum powder was manufactured by ShuiTian Material Technology Co., Ltd. (Shanghai, China). The particle size of the aluminum dust is 5 microns. Approximately $95.15 \%$ of its components is aluminum and $3.72 \%$ is magnesium according to X-ray fluorescence spectrometry (XRF) analysis.

A laser diffraction analyzer (Microtrac S3500, Beituo science and technology, Guangzhou, China) was used to obtain the aluminum particle size and size distribution. The results of $\mathrm{D}_{10}, \mathrm{D}_{50}, \mathrm{D}_{90}, \mathrm{D}_{99}$, and Dav are shown in Figure 1. Figure 2 shows a SEM image of the aluminum particles. The image reveals that the surface of the aluminum particles is compact and smooth. The hydrogen inhibition experimental setup is shown in Figure 3. Sodium tungstate $\left(\mathrm{Na}_{2} \mathrm{WO}_{4} \cdot 2 \mathrm{H}_{2} \mathrm{O}\right)$ was produced by the Tianjin Chemical Reagent Fourth Plant (Tianjin, China).

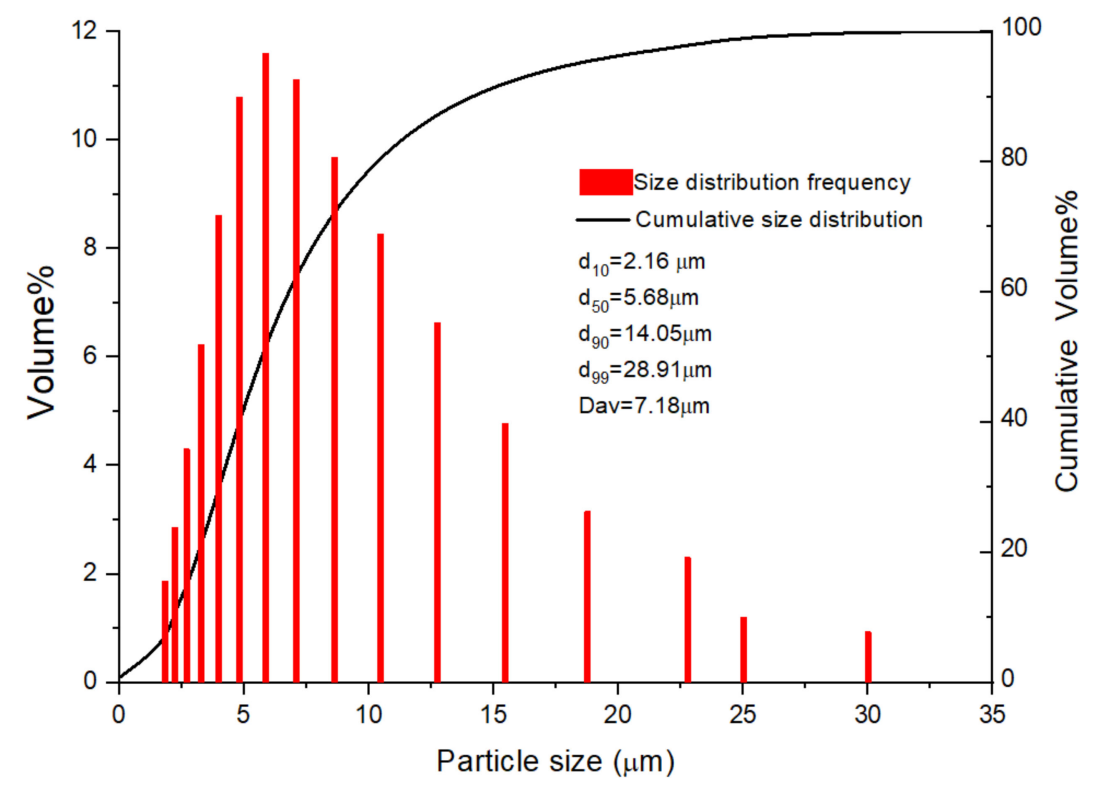

Figure 1. Size distribution map of the aluminum powder.
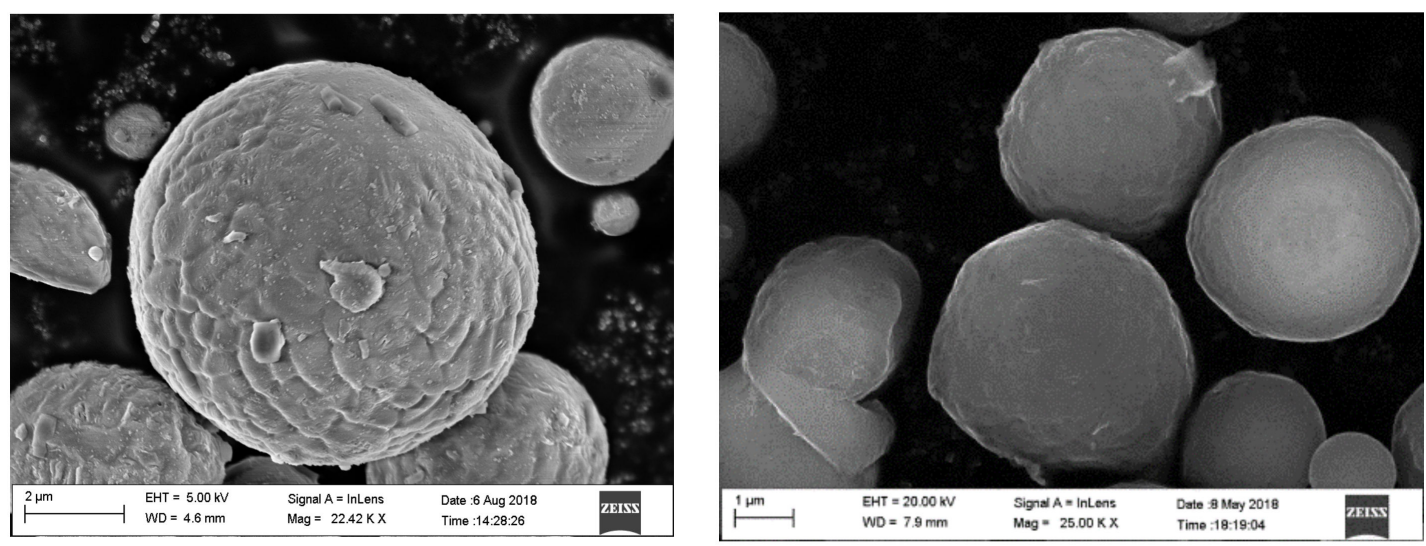

Figure 2. SEM image of the aluminum particles. 


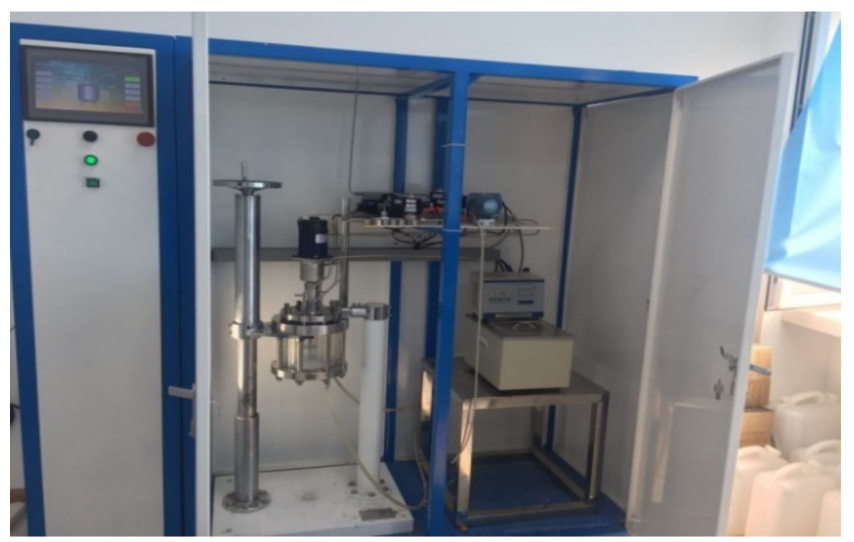

(a)

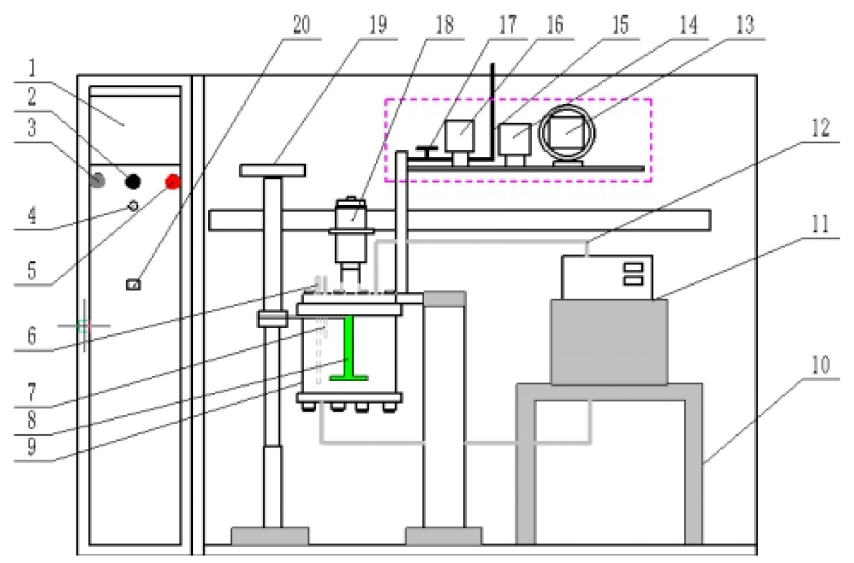

(b)

Figure 3. Physical and structural diagram of the hydrogen inhibition experimental setup. 1. Display, 2. USB export interface, 3. Buzzer, 4. Start switch, 5. Emergency brake device, 6. Temperature sensor, 7. Pressure sensor, 8. Mixer, 9. Reaction kettle, 10. Base, 11. High-temperature circulator, 12. Circulating water pipe, 13. Positive pressure pump, 14. Negative pressure pump, 15. Exhaust pipe, 16. Exhaust pump, 17. Release valve, 18. Stir motor, 19. Operation panel, 20. Light. (a) Physical and schematic diagram of the experimental setup; (b) Plan of the setup.

\subsection{Hydrogen Inhibition Experiment}

According to the work by Wang et al. [4], the initial pressure for each experiment was set to $100 \mathrm{kPa}$. Moreover, the aluminum particles react with water to produce only hydrogen. Therefore, the amount of hydrogen generated can be obtained by the pressure measurement device of the instrument. The mathematical relationship between the hydrogen generated and the pressure is as follows:

$$
\alpha=\frac{\left(P-P_{0}\right)\left(V-V_{\mathrm{w}}\right)}{n_{0} R T}
$$

where $\alpha$-hydrogen evolution, $P$-gas pressure in the reactor, $\mathrm{kPa}, P_{0}$-pressure value in the reactor, $P=100 \mathrm{kPa}, V$-reactor volume, $V=1 \mathrm{~L}, V_{\mathrm{w}}$-volume of the water added into the reactor, $V_{\mathrm{w}}=0.2 \mathrm{~L}, n_{0}$-the theoretical hydrogen moles by reacting all of the $\mathrm{Al}$ dust. R-ideal gas constant, $R=8.314 \mathrm{~J}\left(\mathrm{~mol}^{-1} \mathrm{~K}^{-1}\right)$, T-reaction temperature, $T=323 \mathrm{~K}$.

In Equation (1), as long as the pressure $(P)$ is obtained, the hydrogen evolution $(\alpha)$ can be obtained.

\subsection{Experimental Procedure}

- Perform a gas tightness test. The test was as follows. First, we opened the high-temperature circulator to keep the reaction kettle at $323 \mathrm{~K}$. Then we injected $200 \mathrm{kPa} \mathrm{H}_{2}$ into the reaction kettle 
and waited $24 \mathrm{~h}$. After $24 \mathrm{~h}$, the pressure inside the reaction kettle remained at $200 \mathrm{kPa}$. Then we can proceed to the next step.

- Turned on the hydrogen inhibition setup, and set up the experimental parameters. The parameters including water capacity, aluminum powder quantity, alarm pressure, etc.

- Poured the stirred and mixed sodium tungstate solution into the reaction kettle.

- Added $1.5 \mathrm{~g}$ aluminum powder when the temperature sensor showed the temperature was $323 \mathrm{~K}$, and rotated the control handle to seal the unit.

- Turned on the mixer. After the metal dust is thoroughly mixed with water, turned off the mixer.

- Clicked to start the experiment time. The experiment lasted $12 \mathrm{~h}$. Within the $12 \mathrm{~h}$, the instrument recorded a pressure value every minute, indicating the amount of hydrogen generated by the reaction of aluminum powder and water. The corresponding data of time and pressure are exported after the experiment ends.

- $\quad$ Processed the data.

\subsection{Characterizations}

SEM was used to characterize the appearance of aluminum particles; the aluminum particles were characterized before and after their reaction with sodium tungstate solutions. EDS was used to characterize the elemental distribution on the surface of the aluminum particles after they were reacted with different concentrations of sodium tungstate solutions, and a laser diffraction analyzer was used to determine the size distribution of the aluminum particles.

X-ray diffraction (XRD) and X-ray photoelectron spectroscopy (XPS) analyses were conducted to identify the characteristics of the coating with good inhibition effect that precipitated on the surface of the aluminum powder. The main equipment used in this experiment is listed in Table 1.

Table 1. The main instruments used in this experiment.

\begin{tabular}{cccc}
\hline Experiment Name & Instrument & Model & Manufacturer \\
\hline $\begin{array}{c}\text { Hydrogen inhibition } \\
\text { experiment }\end{array}$ & $\begin{array}{c}\text { Hydrogen inhibition } \\
\text { experiments }\end{array}$ & Custom instrument & N/A \\
\hline SEM & $\begin{array}{c}\text { Scanning electron } \\
\text { microscope }\end{array}$ & Ultra Plus & $\begin{array}{c}\text { Zeiss Microscope Co., Ltd. } \\
\text { Oberkochen, Germany }\end{array}$ \\
\hline EDS & $\begin{array}{c}\text { Energy dispersive } \\
\text { spectroscopy }\end{array}$ & SSX-550 & $\begin{array}{c}\text { Shimadzu Corporation, } \\
\text { Shanghai, China }\end{array}$ \\
\hline XPS & $\begin{array}{c}\text { X-ray photoelectron } \\
\text { spectrometer }\end{array}$ & Kratos Ultra DLD & $\begin{array}{c}\text { Shanghai Aitanpu New Material } \\
\text { Technology Co., Ltd., Shanghai, China }\end{array}$ \\
\hline XRD & X-ray diffraction & X'Pert PRO & PANalytical B.V., Almelo, Holland \\
\hline
\end{tabular}

\section{Results and Discussion}

Since the sample content of the aluminum particle is $95.15 \%$, we only consider on how to inhibit the reaction of aluminum with water in the experiment.

\subsection{Results of the Hydrogen Inhibition Experiments}

\subsubsection{Hydrogen Evolution Curves}

According to Equation (1), if we obtain the corresponding data of time and pressure, we can get the corresponding data of time and hydrogen evolution $\alpha$. Then we use the curve to describe the relationship between them, as shown in Figure 4. 


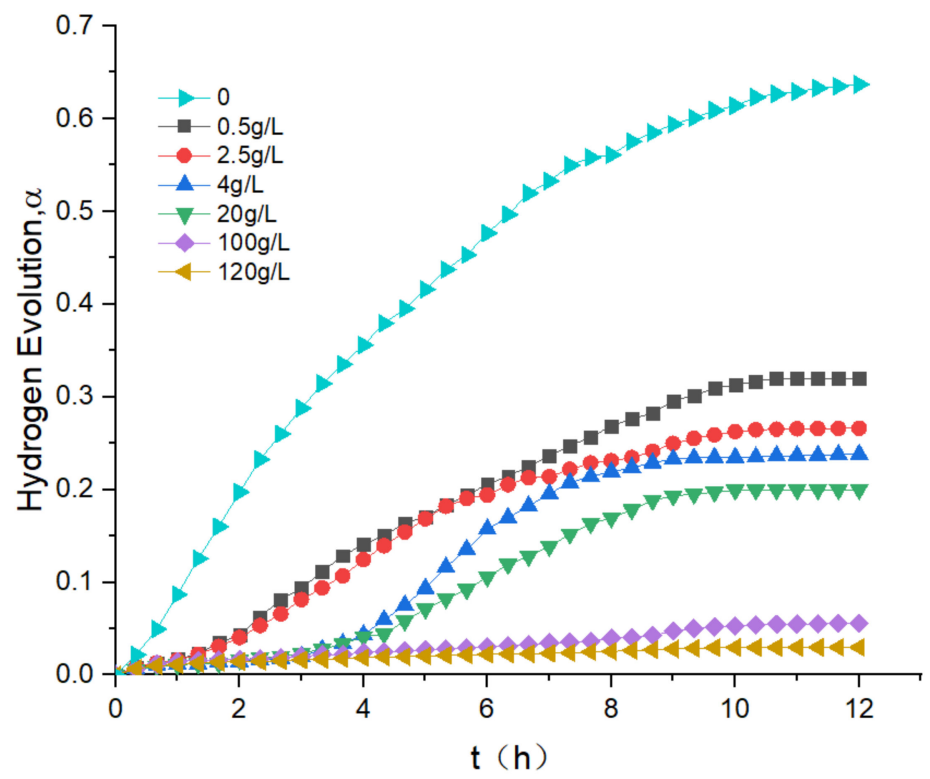

Figure 4. Hydrogen evolution curves of the aluminum particles after their reaction with the sodium tungstate solution at different concentrations.

Figure 4 reveals the corresponding data of time and hydrogen evolution $\alpha$ of the reaction between the same weight of aluminum dust and 7 different concentrations of the sodium tungstate solution. The reactions lasted for approximately $12 \mathrm{~h}$. As the concentration of sodium tungstate solution was increased, the value of $\alpha$ gradually decreased. If we added $0.5 \mathrm{~g} / \mathrm{L}$ sodium tungstate, the value of $\alpha$ was no more than 0.35 , which indicated that the reaction between aluminum particles and water has been inhibited. When the concentration of the sodium tungstate solution was greater than or equal to $100 \mathrm{~g} / \mathrm{L}$, the value of $\alpha$ approached 0 . The hydrogen production that was inhibited was significantly different from the control group. Moreover, when the concentration of sodium tungstate added was greater than $100 \mathrm{~g} / \mathrm{L}$, the inhibition effect did not change significantly with the increased concentration. In summary, the optimal concentration of sodium tungstate for the inhibition of the reaction between aluminum powder with water is $100 \mathrm{~g} / \mathrm{L}$.

\subsubsection{SEM and EDS}

To learn more about the inhibitory effect of sodium tungstate on the corrosion of aluminum dust in water, the two samples (after the Al particles reacted with 2.5 and $100 \mathrm{~g} / \mathrm{L}$ sodium tungstate solutions) were studied with SEM and EDS. A scanning electron microscope (SEM) with high resolution $(\leq 0.8 \mathrm{~nm}$ $\cong 15 \mathrm{kV}, \leq 1.6 \mathrm{~nm} \cong 1 \mathrm{kV})$ and excellent acceleration voltage $(0.02-30 \mathrm{kV})$ was used in the experiments. The surface morphology and surface composition of the reaction product samples were characterized to compare with the SEM image of the previous aluminum ball (as shown in Figure 2).

According to these studies [19-22], we understood the mechanism of metal dust reacting with water. This mechanism is similar to the mechanism of metal corrosion. The chemical equations involved are as follows:

$$
\begin{gathered}
4 \mathrm{Al}+3 \mathrm{O}_{2} \rightarrow 2 \mathrm{Al}_{2} \mathrm{O}_{3} \\
\mathrm{Al}_{2} \mathrm{O}_{3}+3 \mathrm{H}_{2} \mathrm{O} \stackrel{\Delta}{\rightarrow} 2 \mathrm{Al}(\mathrm{OH})_{3} \\
2 \mathrm{Al}+6 \mathrm{H}_{2} \mathrm{O} \stackrel{\Delta}{\rightarrow} 2 \mathrm{Al}(\mathrm{OH})_{3}+3 \mathrm{H}_{2} \uparrow \\
2 \mathrm{Al}(\mathrm{OH})_{3}+2 \mathrm{Al} \stackrel{\Delta}{\rightarrow} 2 \mathrm{Al}_{2} \mathrm{O}_{3}+3 \mathrm{H}_{2} \uparrow
\end{gathered}
$$

The surface of the aluminum particles exposed to the air is oxidized to alumina. Alumina is very stable and protects aluminum from continuing to react with oxygen. However, after being mixed with 
the aqueous solution, the alumina and water undergo a hydration reaction, and the outermost layer of alumina reacts with water to form aluminum hydroxide. As the temperature gradually increases to $323 \mathrm{~K}$, more aluminum hydroxide is formed, and the tension of the aluminum oxide coating and the aluminum hydroxide coating is increased. When the tension exceeds the critical tension of the coating, the coating is broken. Then, the exposed aluminum core reacts directly with the aluminum hydroxide, and the generated hydrogen causes the coating to rupture more severely; thus, the water directly reacts with the aluminum core, and the reaction speed is rapidly increased until the aluminum is substantially oxidized with water to aluminum hydroxide and precipitated alumina. The formation process of an aluminum particle hydrate layer can be seen in Figure 5.

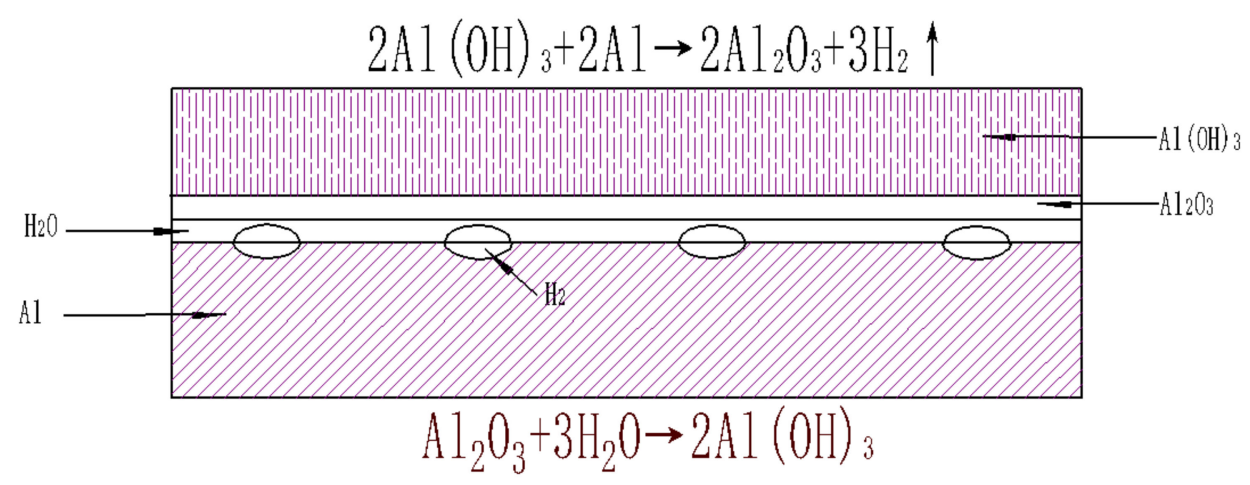

Figure 5. The hydration reaction and the hydrogen production reaction on the surface of aluminum particles.

After adding sodium tungstate, the inhibitor reacts with aluminum hydroxide to form a poorly soluble precipitate, which is adsorbed on the aluminum hydroxide coating and prevents further reactions from occurring [12,23].

Figures 6 and 7 show the SEM photographs and W mapping image of the $2.5 \mathrm{~g} / \mathrm{L}$ sodium tungstate solution reaction product (A sample) and $100 \mathrm{~g} / \mathrm{L}$ sodium tungstate solution reaction product (B sample), respectively. In contrast to the aluminum particles in Figure 2, the surface of the A sample is rougher and has a large amount of needle-like and sticky substances. The surface of the B sample is as smooth as aluminum particles shown in Figure 2, which means that the coating protects the core well. Since the EDS probe depth is only $1 \mu \mathrm{m}$ and the aluminum particles have a Dav of $7.18 \mu \mathrm{m}$, so its EDS elemental analysis only corresponds to the surface position [24-27].
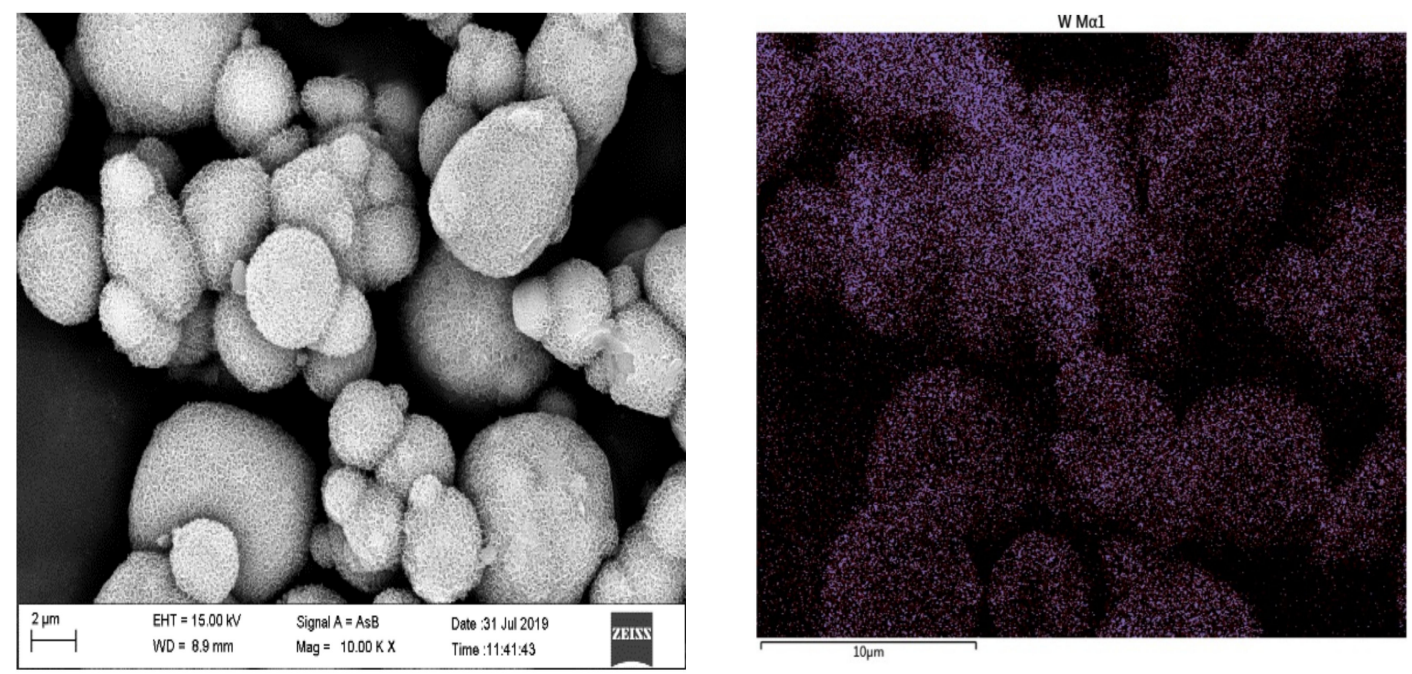

Figure 6. SEM image and EDS W mapping image of the aluminum particles after reaction with $100 \mathrm{~g} / \mathrm{L}$ sodium tungstate solution. 

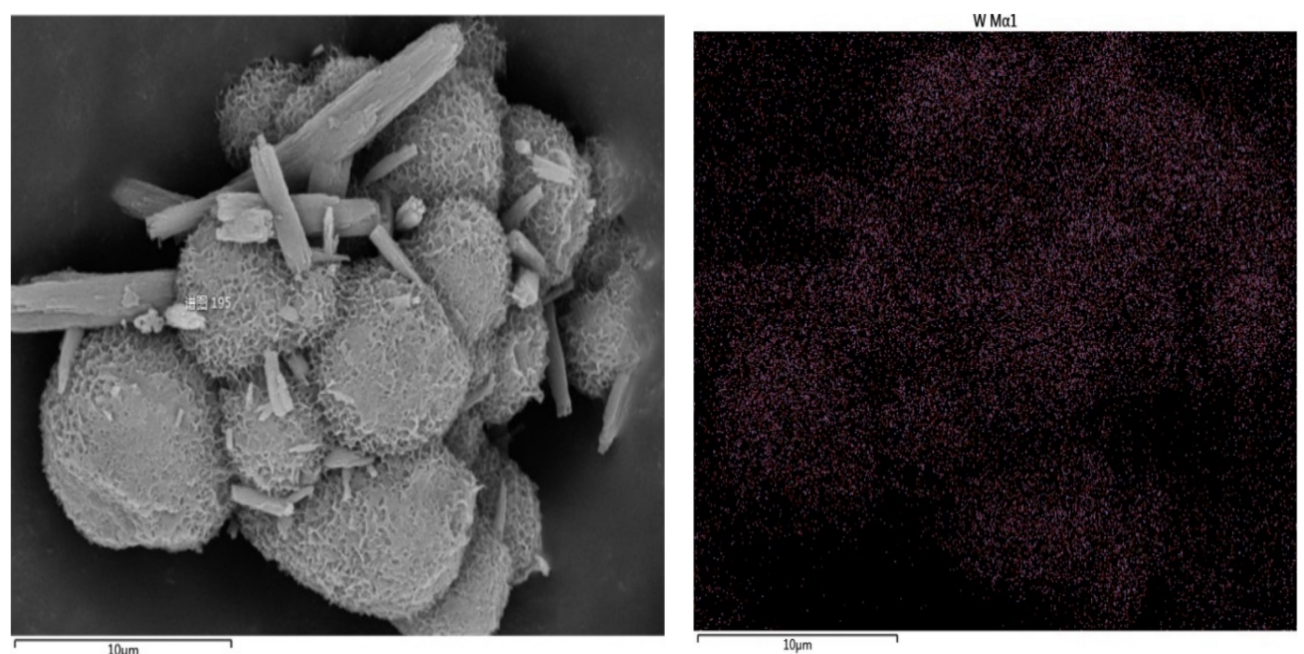

Figure 7. SEM image and EDS W mapping image of the aluminum particles after reaction with $2.5 \mathrm{~g} / \mathrm{L}$ sodium tungstate solution.

According to the EDS elemental analysis of the W distribution as shown in Figures 8 and 9, the substance of A sample has a lower content of elemental W than B sample. This is because no sufficient tungstate precipitate is formed on the aluminum particles coating, and the surface contains a large amount of $\mathrm{Al}(\mathrm{OH})_{3}$, which is easily soluble in hot water. A part of the aluminum globe is wrapped by the aluminum tungstate without being corroded, and the other part of the aluminum globe that is not wrapped by the aluminum tungstate is corroded into the needle shape.
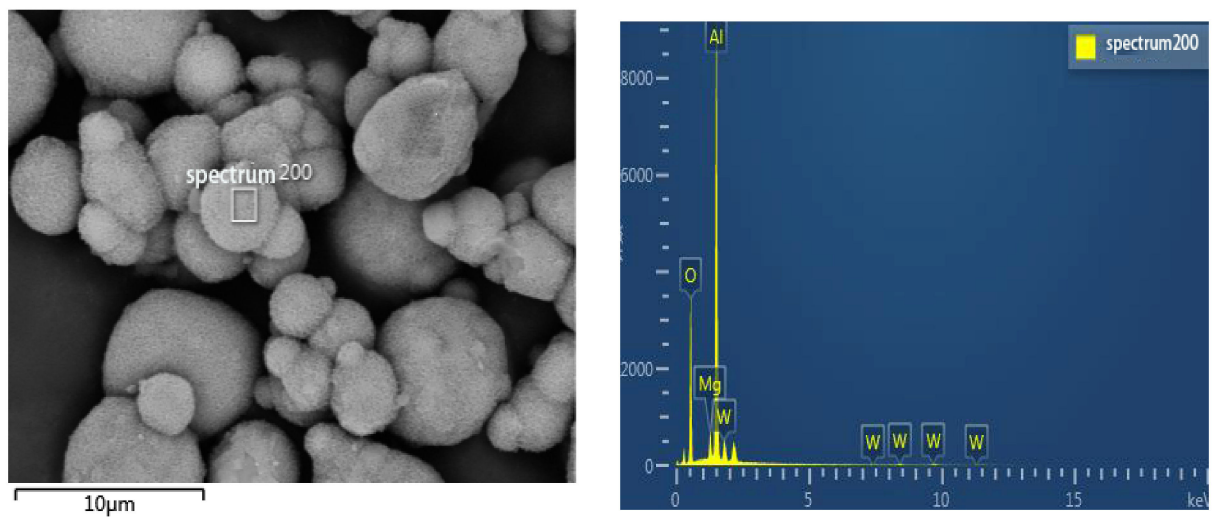

Figure 8. EDS elemental analysis of the aluminum particles after reaction with $100 \mathrm{~g} / \mathrm{L}$ sodium tungstate solution.
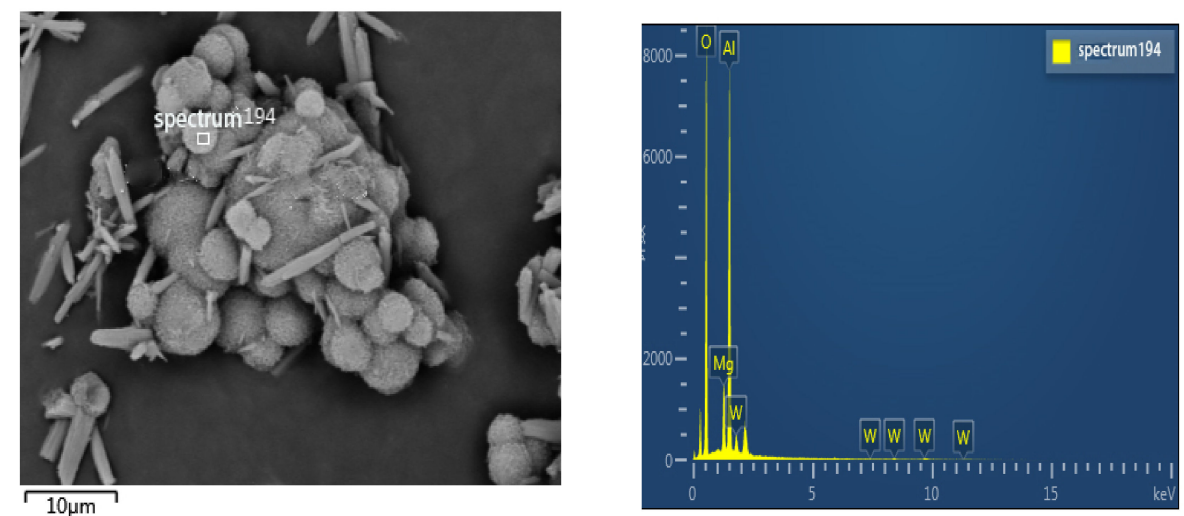

Figure 9. EDS elemental analysis of the aluminum particles after their reaction with $2.5 \mathrm{~g} / \mathrm{L}$ sodium tungstate solution. 
Comparing Tables 2 and 3, the elemental point sweep analysis of the aluminum spheres of two different concentrations of reaction products reveals that the $B$ sample has a higher content of elemental $\mathrm{W}$ and elemental $\mathrm{Al}$ and has a lower content of elemental $\mathrm{O}$. These results could prove that the $\mathrm{A}$ sample contains more aluminum tungstate and less aluminum hydroxide, which further inhibits aluminum corrosion.

Table 2. The mass percentage of elements in the $100 \mathrm{~g} / \mathrm{L}$ sodium tungstate solution.

\begin{tabular}{cccc}
\hline EDS Elemental Analysis & Element & Mass Percentage & Atomic Percentage \\
\hline & $\mathrm{O}$ & 36.92 & 53.35 \\
$100 \mathrm{~g} / \mathrm{L}$ sodium & $\mathrm{Mg}$ & 2.92 & 2.78 \\
tungstate solution & $\mathrm{Al}$ & 49.65 & 42.55 \\
& $\mathrm{~W}$ & 10.51 & 1.32 \\
& total & 100.00 & 100.00 \\
\hline
\end{tabular}

Table 3. The mass percentage of elements in the $2.5 \mathrm{~g} / \mathrm{L}$ sodium tungstate solution reaction product.

\begin{tabular}{cccc}
\hline EDS Elemental Analysis & Element & Mass Percentage & Atomic Percentage \\
\hline & $\mathrm{O}$ & 54.63 & 69.20 \\
$2.5 \mathrm{~g} / \mathrm{L}$ sodium tungstate & $\mathrm{Mg}$ & 5.72 & 4.77 \\
solution reaction product & $\mathrm{Al}$ & 33.81 & 25.39 \\
& $\mathrm{~W}$ & 5.84 & 0.64 \\
& total & 100.00 & 100.00 \\
\hline
\end{tabular}

\subsubsection{XRD and XPS}

$\mathrm{X}$-ray diffraction $(\mathrm{XRD})$ using a $\mathrm{Cu}$ line source by ceramic X-ray tube and vertical goniometer $(P=2200 \mathrm{~W})$ was used to identify and classify the inhibitory coating product of the hydrogen inhibition reaction. The results are shown in Figure 10. The XRD peak of the sample was mostly aluminum, and two weak peaks of $\mathrm{Al}_{2}\left(\mathrm{WO}_{4}\right)_{3}$ and one weak peak of $\mathrm{WO}_{3}$ were observed. Here, $\mathrm{WO}_{3}$ present in the pattern was amorphous since it possessed a wide peak at 10-23.1 eV [28,29].

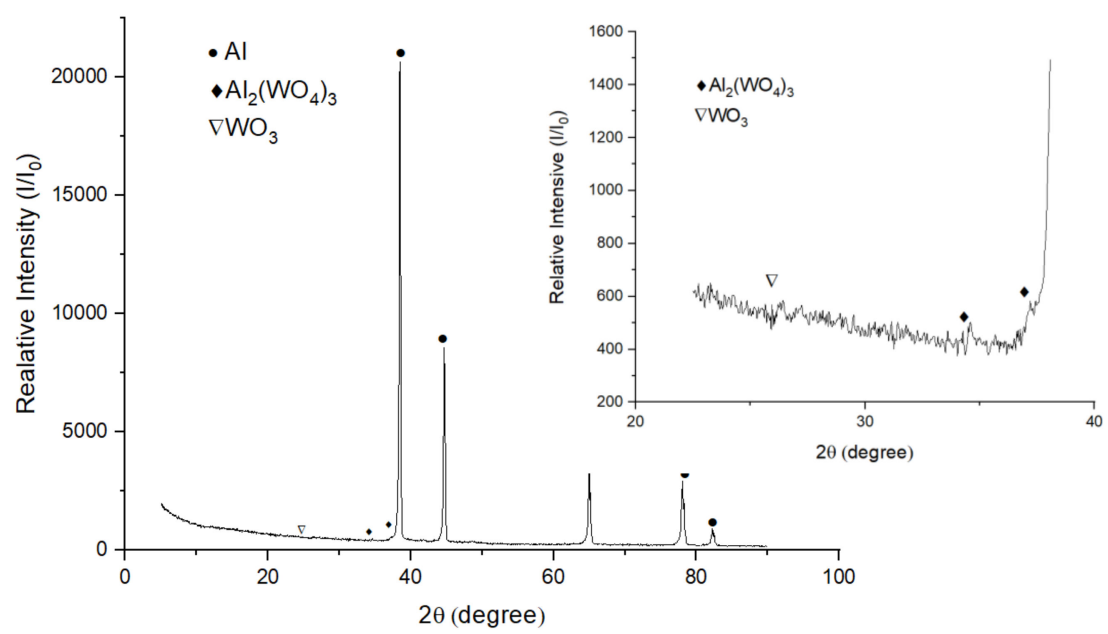

Figure 10. XRD pattern of the coating formed in the aluminum solution with the addition of $100 \mathrm{~g} / \mathrm{L}$ sodium tungstate.

The results reveal that the aluminium particles were not consumed in the $100 \mathrm{~g} / \mathrm{L}$ sodium tungstate solution and the presence of $\mathrm{Al}_{2}\left(\mathrm{WO}_{4}\right)_{3}$ and $\mathrm{WO}_{3}$ might lead to the inhibition. In order to verify our conjecture, XPS is required. X-ray photoelectron spectroscopy (XPS) by spectrometer ES-2404 with hemispherical sector energy analyzer $(\mathrm{E} \mathrm{Al} K \alpha=1486.6 \mathrm{eV}, P=450 \mathrm{~W})$ can measure the energy of photoelectrons to determine the chemical composition of coatings of aluminum particles. The shift in 
the binding energies was calibrated with the $C$ 1s peak of the adventitious carbon at a binding energy (BE) of $284.68 \mathrm{eV}$ as a reference.

Figure 11 shows the XPS spectrum of the characteristic satellite peaks of the coating at $0 \sim 1400 \mathrm{eV}$. The peaks near the binding energies of 73 and $75 \mathrm{eV}$ were $\mathrm{Al}^{3+}$, while the peaks between 35 and $40 \mathrm{eV}$ belonged to $\mathrm{W} 4 \mathrm{f}$. The coating was heavily populated with $\mathrm{Al} 2 \mathrm{p}, \mathrm{C} 1 \mathrm{~s}$ and $\mathrm{O} 1 \mathrm{~s}$ but with a very low percentage of $\mathrm{Na} 1 \mathrm{~s}$ and $\mathrm{W} 4 \mathrm{f}$. Here, $\mathrm{C} 1 \mathrm{~s}$ was a contaminant that could result from adventitious carbon. Here, the presence of $\mathrm{Na}$ 1s may be due to residual sodium tungstate on the sample, which was not rinsed sufficiently. The coatings of $\mathrm{Al} 2 \mathrm{p}$ and $\mathrm{W} 4 \mathrm{f}$ after the reaction were studied carefully using XPS analysis, as shown in Figures 12 and 13, respectively. Figure 12 shows the Al 2p characteristic satellite peaks at $73.8 \mathrm{eV}$. Only one peak corresponding to $\mathrm{Al}^{3+}$ was observed. The $\mathrm{Al} 2 \mathrm{p} \mathrm{BE}$ associated with aluminum tungstate is $73.8 \mathrm{eV}$ [30]. Figure 13 shows the $\mathrm{W} 4 \mathrm{f}$ for coatings formed in the aluminum solution with the addition of $100 \mathrm{~g} / \mathrm{L}$ sodium tungstate. The spectrum shows the binding energies of $36.12 \mathrm{eV}\left(\mathrm{W}_{4} \mathrm{f}_{7 / 2}\right)$ and $38.23 \mathrm{eV}\left(\mathrm{W}_{4} \mathrm{f}_{5 / 2}\right)$, which correspond to $\mathrm{WO}_{3}$ and $\mathrm{Na}_{2} \mathrm{WO}_{4}$, respectively. There is no free state of $\mathrm{W}$ in the coating since it has a $\mathrm{W} 4 \mathrm{f}_{7 / 2}$ peak from $30.0-31.0 \mathrm{eV}$ [31-33].

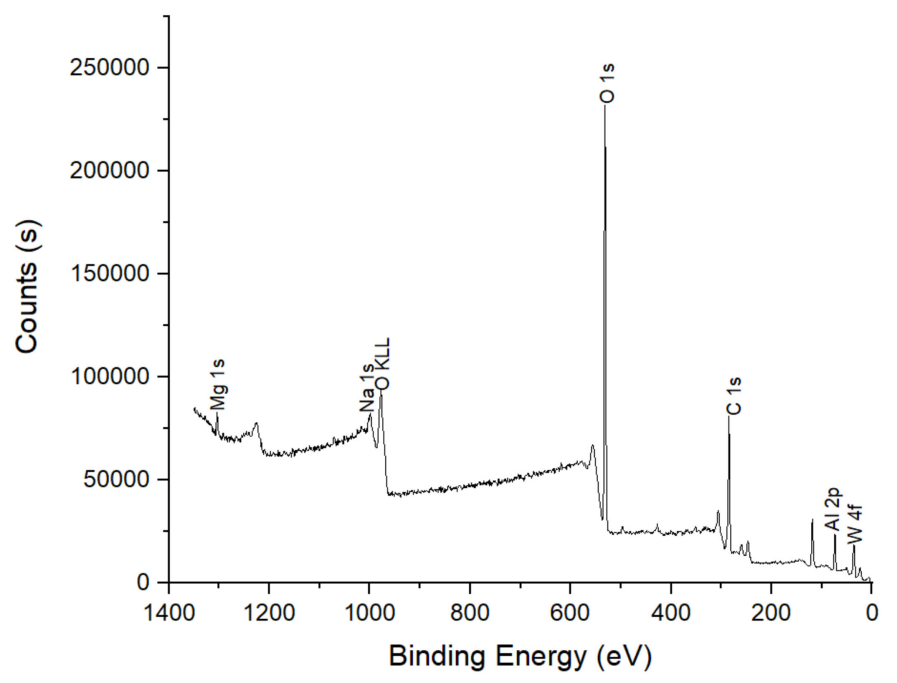

Figure 11. XPS spectrum of the coating formed in the aluminum solution with the addition of $100 \mathrm{~g} / \mathrm{L}$ sodium tungstate.

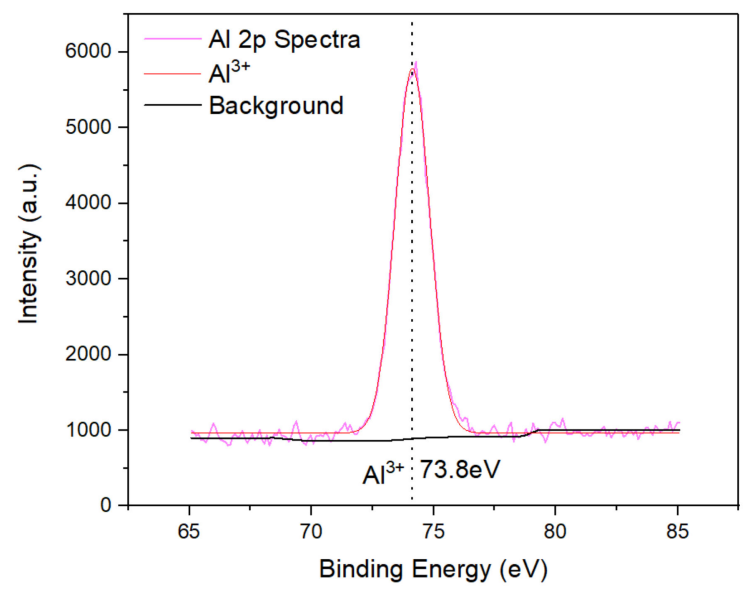

Figure 12. XPS-specific spectrum of $\mathrm{Al} 2 \mathrm{p}$ for coatings formed in aluminum solution with the addition of $100 \mathrm{~g} / \mathrm{L}$ sodium tungstate. 


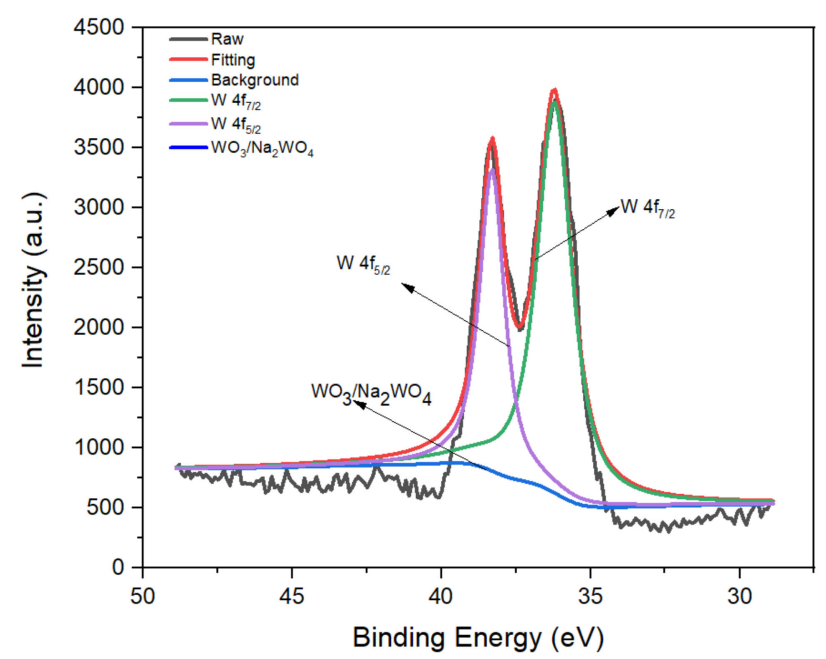

Figure 13. XPS specific spectrum of $\mathrm{W} 4 \mathrm{f}$ for the coating formed in the aluminum solution with the addition of $100 \mathrm{~g} / \mathrm{L}$ sodium tungstate.

\subsubsection{Summary of the Experimental Results}

According to the hydrogen evolution curves, we know that the optimal concentration of sodium tungstate for the inhibition of the reaction between aluminum powder with water is $100 \mathrm{~g} / \mathrm{L}$. SEM and EDS reveal that the reaction product with excellent effect is suppressed, and more spherical substances coatings are formed than the others. As can be seen from the results of XRD and XPS, coatings of these spherical materials contains a certain amount of aluminum tungstate and very small dose of tungsten trioxide. These coatings protect the aluminum particles from reacting with water and keep aluminum particles spherical.

\subsection{Physicochemical Mechanisms}

\subsubsection{The Equation for Inhibitory Reactions}

Since the deionized water mixed with aluminum powder in the experiment is slightly acidic, during the initial stage of the reaction, some sodium tungstate may react with $\mathrm{H}^{+}$in the process of adding water mixed with aluminum powder and sodium tungstate into the reactor; thus, a very small amount of $\mathrm{WO}_{3}$ is formed.

This is also the reason why the weak peak of $\mathrm{WO}_{3}$ was detected in the XRD pattern and XPS spectrum and why the aqueous solution containing sodium tungstate is slightly alkaline. The chemical reaction is shown in Equation (6):

$$
\mathrm{WO}_{4}^{2-}+2 \mathrm{H}^{+} \rightarrow \mathrm{H}_{2} \mathrm{O}+\mathrm{WO}_{3}
$$

According to the previous SEM data, the amount of aluminum tungstate precipitated was small, thus it was present in the XRD peak results. The peak of aluminum is very strong, indicating that most of the aluminum remains after the reaction, and the inhibition effect is very good.

The aluminum hydroxide coating on the aluminum core reacts with sodium tungstate to form aluminum tungstate precipitates. The chemical reaction is shown in Equation (7):

$$
2 \mathrm{Al}(\mathrm{OH})_{3}+3 \mathrm{WO}_{4}^{2-} \rightarrow \mathrm{Al}_{2}\left(\mathrm{WO}_{4}\right)_{3}+6 \mathrm{OH}^{-}
$$

The resulting $\mathrm{OH}^{-}$also causes the solution to become alkaline to a certain extent, so that the aluminum tungstate coating and the aluminum oxide coating are less likely to be destroyed. 


\subsubsection{Chemical Kinetic Model}

According to the Gai's research [34], the chemical kinetic model for the reaction of aluminium powder with water conforms to the shrinking core. Furthermore, Martínez-Salazar et al. [35] proved that a modified traditional shrinking core model can be developed to analyze the flat plate aluminum corrosion in aqueous acid solutions.

In this study, the physical and chemical mechanism of the reaction between aluminum particles and water is also established based on the shrinking core model. We take the hydrogen evolution data of aluminum dust reacted with $2.5 \mathrm{~g} / \mathrm{L}$ sodium tungstate solution as an example. Figure 14 shows that the hydrogen evolution data fits well with the shrinking core model. The rate constant is $0.01123 h^{-1}$. Different concentrations of sodium tungstate solution were al used to fit Equation (8) for the hydrogen evolution data. The calculated rate constants are shown in Table 4. With the increasing concentration of the sodium tungstate solutions, the $\mathrm{k}$ decreases gradually. When the concentration of sodium tungstate reached $100 \mathrm{~g} / \mathrm{L}, k$ was almost zero, and this indicated that when the concentration of sodium tungstate increased to a certain extent, the reaction between aluminum and water can be effectively inhibited. The results are consistent with the shrinking core model shown in the previous study:

$$
1-(1-\alpha)^{\frac{1}{3}}=k t
$$

where $\mathrm{t}$ represents reaction time $(h)$ and $k$ represents the rate constant $\left(h^{-1}\right)$.

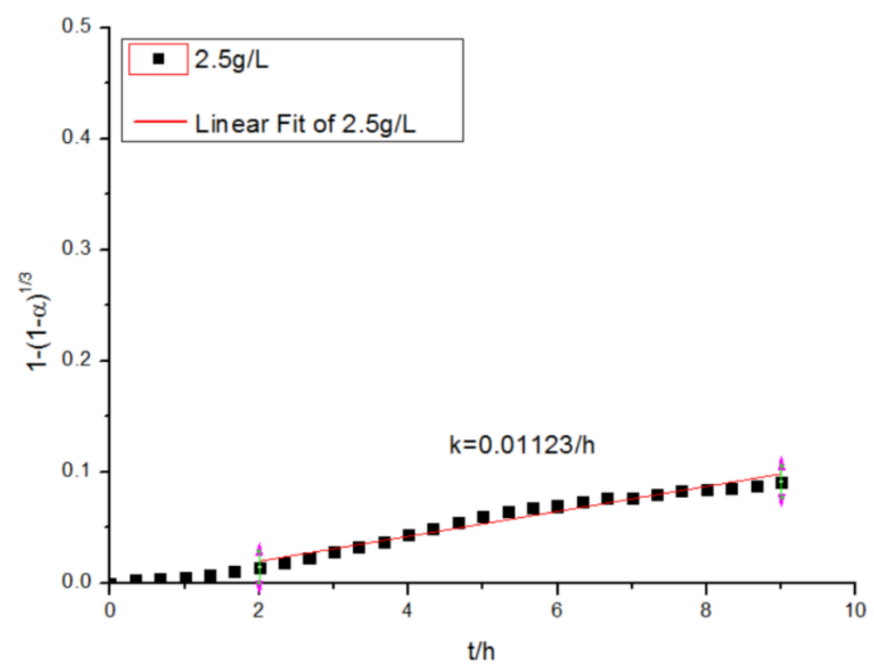

Figure 14. Chemical kinetic curve of $2.5 \mathrm{~g} / \mathrm{L}$ sodium tungstate solution.

Table 4. Reaction rate constants at $T=323 \mathrm{~K}$.

\begin{tabular}{ccc}
\hline $\begin{array}{c}\text { Concentration of the Sodium } \\
\text { Tungstate Solution }(\mathrm{g} / \mathrm{L})\end{array}$ & Rate Constant $\left(\boldsymbol{h}^{\mathbf{- 1})}\right.$ & Initial $\mathbf{p H}$ Value \\
\hline 0 & 0.02924 & 6.7 \\
0.5 & 0.01313 & 7.4 \\
2.5 & 0.01123 & 7.8 \\
4 & 0.00791 & 8.1 \\
20 & 0.00351 & 8.9 \\
100 & 0.000147 & 9.7 \\
120 & 0.000109 & 9.7 \\
\hline
\end{tabular}

3.2.3. The Langmuir Adsorption Isotherm of the Sample

Through our study of inhibitors, we found that the types of inhibitors include precipitated, oxidized and adsorbed types. The data of the different concentrations of adsorbed inhibitors that reacted with aluminum conformed to the Langmuir adsorption model [36]. 
The Langmuir adsorption isotherm is shown in Equation (9), the formula simplification comes from the work by Helal et al. [37]. If the correlation coefficient and slope are both close to 1, then we can verify that the adsorption model of sodium tungstate and aluminum particles agrees with the Langmuir adsorption isotherm. In the Langmuir adsorption modified model, the isothermal equation is in accordance with Equation (9):

$$
\frac{c}{\theta}=\frac{1}{K}+c
$$

where $C$ is the mass concentration of inhibitors, $g / L, K$ is the adsorption equilibrium constant, $\mathrm{L} / \mathrm{g}$ and $\theta$ is the surface coverage.

In each experiment, we added $1.5 \mathrm{~g}$ of aluminum powder, $200 \mathrm{~mL}$ of deionized water and different amounts of sodium tungstate. In Equation (1), we can treat $\alpha$ as the ratio of the amount of hydrogen generated by the reaction of aluminum powder with sodium tungstate solution to the amount of hydrogen generated by all $1.5 \mathrm{~g}$ aluminum powder reaction in an ideal state, that is, the ratio of the amount of aluminum reacted to the amount of $1.5 \mathrm{~g}$ aluminum powder. The surface coverage is the ratio of the amount of aluminum covered coatings unreacted to the amount of $1.5 \mathrm{~g}$ aluminum powder. Then we can get the Equation (10) below to obtain $\theta$;

$$
\theta=1-\alpha
$$

The linear correlation of $\mathrm{C} / \theta-\mathrm{C}$ for the sodium tungstate inhibitor is shown in Figure 15. The linear regression parameters of $\mathrm{C} / \theta-\mathrm{C}$ are shown in Table 5 . We can see that both the correlation coefficient and slope are close in a value to 1 , which indicates a good correlation. Sodium tungstate is an adsorption inhibitor, which means that sodium tungstate forms a dense monolayer on the surface of Al dust, effectively inhibiting the further reaction between aluminum particles with water.

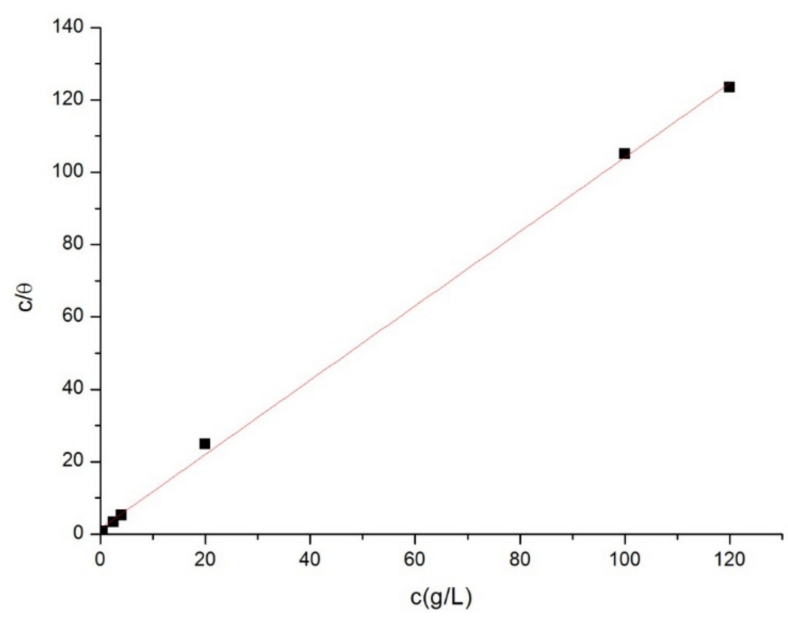

Figure 15. Langmuir fitting curve of sodium tungstate.

Table 5. Linear fitting parameters of $C / \theta-C$.

\begin{tabular}{cccc}
\hline Inhibitor & K & Slope & Correlation Coefficient $(r)$ \\
\hline Sodium tungstate & 0.65 & 1.02 & 0.999 \\
\hline
\end{tabular}

\section{Conclusions}

Due to the reaction between aluminum particles and water, hydrogen generation in a wet dust removal system poses a risk of fire and explosion. The studies investigated the possibility and the mechanism of how sodium tungstate can be used to inhibit the generation of hydrogen in metal dust with water.

From the obtained results, the adaptability of sodium tungstate to inhibit the reaction of aluminum with water has been demonstrated. When the sodium tungstate concentration reached $100 \mathrm{~g} / \mathrm{L}$, 
the production of hydrogen approached 0 . The shrinking core kinetic models shows that the inhibition effect is excellent. The Langmuir adsorption model shows that sodium tungstate behaves as an adsorption inhibitor. According to the XRD, XPS, and SEM with EDS results, the inhibitory coating that formed on the aluminium particles after reaction with the $100 \mathrm{~g} / \mathrm{L}$ sodium tungstate solution contained aluminum tungstate and tungsten trioxide.

In contrast to expensive hydrogen removal equipment and exhaust systems, the green and environmentally friendly inhibitor sodium tungstate is thus a better choice in the wet dust removal system and achieves inherent safety. The proposed use of aluminum tungstate also conforms to the inherent safety requirements.

Author Contributions: K.X. and Y.W. conceived and designed the research; B.Z. wrote the paper. X.Z. and X.Y. carried out the experiments; J.G. entered the discussion. All authors have read and agreed to the published version of the manuscript.

Funding: The work presented in this study forms part of the research funded by the National Key Research and Development Program of China (Grant Nos. 2017YFC0805100 and 2018YFC0808406). These funding sources are greatly appreciated.

Conflicts of Interest: The authors declare no conflict of interest.

\section{References}

1. Soler, L.; Candela, A.M.; Macanás, J.; Muñoz, M.; Casado, J. In situ generation of hydrogen from water by aluminum corrosion in solutions of sodium aluminate. J. Power Sources 2009, 192, 21-26. [CrossRef]

2. Li, G.; Yang, H.-X.; Yuan, C.-M.; Eckhoff, R. A catastrophic aluminium-alloy dust explosion in China. J. Loss Prev. Process. Ind. 2016, 39, 121-130. [CrossRef]

3. Paltrinieri, N.; Khan, F.; Amyotte, P.R.; Cozzani, V. Dynamic approach to risk management: Application to the Hoeganaes metal dust accidents. Process. Saf. Environ. Prot. 2014, 92, 669-679. [CrossRef]

4. Myers, T. Reducing aluminum dust explosion hazards: Case study of dust inerting in an aluminum buffing operation. J. Hazard. Mater. 2008, 159, 72-80. [CrossRef] [PubMed]

5. Jensen, M.B.; Peterson, M.J.; Jadhav, N.; Gelling, V. SECM investigation of corrosion inhibition by tungstateand vanadate-doped polypyrrole/aluminum flake composite coatings on AA2024-T3. Prog. Org. Coat. 2014, 77, 2116-2122. [CrossRef]

6. Gray, J.; Luan, B. Protective coatings on magnesium and its alloys - a critical review. J. Alloy. Compd. 2002, 336, 88-113. [CrossRef]

7. Tseng, C.-C.; Lee, J.-L.; Kuo, T.-H.; Kuo, S.-N.; Tseng, K.-H. The influence of sodium tungstate concentration and anodizing conditions on microarc oxidation (MAO) coatings for aluminum alloy. Surf. Coatings Technol. 2012, 206, 3437-3443. [CrossRef]

8. Uhlig, H.H.; King, P.F. The Flade potential of iron passivated by various inorganic corrosion inhibitors. J. Electrochem. Soc. 1959, 106. [CrossRef]

9. Sanni, S.E.; Ewetade, A.P.; Emetere, M.E.; Agboola, O.; Okoro, E.E.; Olorunshola, S.J.; Olugbenga, T.S. Enhancing the inhibition potential of sodium tungstate towards mitigating the corrosive effect of Acidithiobaccillus thiooxidan on X-52 carbon steel. Mater. Today Commun. 2019, 19, 238-251. [CrossRef]

10. Javidi, M.; Omidvar, R. Synergistic inhibition behavior of sodium tungstate and penicillin $\mathrm{G}$ as an eco-friendly inhibitor on pitting corrosion of 304 stainless steel in $\mathrm{NaCl}$ solution using Design of Experiment. J. Mol. Liq. 2019, 291, 111330. [CrossRef]

11. Yao, Z. Study on Green Inhibitor of Magnesium Alloy and Its Inhibitory Mechanism. Ph.D. Thesis, Chongqing University, Chongqing, China, 2008. (In Chinese).

12. Yan, L.; Zhu, L. Progress in Tungstate Inhibition Mechanism. J. Mater. Prot. 2000, 11, 29-31. (In Chinese)

13. Wang, Y.; Xu, K.; Wang, B.; Zhang, J. Hydrogen inhibition in a wet aluminum dust collection system using dichromate solution. RSC Adv. 2017, 7, 47867-47876. [CrossRef]

14. Wang, Y.; Xu, K.; Li, L. Inhibition of the reaction between aluminium dust and water based on the HIM. RSC Adv. 2017, 7, 33327-33334. [CrossRef]

15. Wang, Y.; Xu, K.; Wang, B.; Wang, Q. Hydrogen inhibition by using $\mathrm{Cr}(\mathrm{NO} 3) 3 \cdot 9 \mathrm{H} 2 \mathrm{O}$ in the wet dust removal system for the treatment of aluminum dust. Int. J. Hydrog. Energy 2018, 43, 2514-2523. [CrossRef] 
16. Xu, K.; Wang, Y.; Shen, R.; Wang, Q. Inhibition of hydrogen production reactions in the wet dust removal system using $\mathrm{CeCl} 3$ solutions. Int. J. Hydrogen Energy 2018, 43, 14859-14865. [CrossRef]

17. Zheng, X.; Xu, K.; Wang, Y.; Shen, R.; Wang, Q. Study of hydrogen explosion control measures by using 1-phenylalanine for aluminum wet dust removal systems. RSC Adv. 2018, 8, 41308-41316. [CrossRef]

18. Zheng, X.; Xu, K.; Wang, Y.; Wang, Q. Hydrogen inhibition method for preventing hydrogen explosion accident in wet dust removal systems. Int. J. Hydrog. Energy 2019, 44, 17195-17201. [CrossRef]

19. Deng, Z.-Y.; Ferreira, J.M.F.; Tanaka, Y.; Ye, J. Physicochemical Mechanism for the Continuous Reaction of Al2O3-Modified Aluminum Powder with Water. J. Am. Ceram. Soc. 2007, 90, 1521-1526. [CrossRef]

20. Gai, W.-Z.; Deng, Z.-Y. Effect of initial gas pressure on the reaction of Al with water. Int. J. Hydrog. Energy 2014, 39, 13491-13497. [CrossRef]

21. Deng, Z.-Y.; Tang, Y.-B.; Zhu, L.-L.; Sakka, Y.; Ye, J. Effect of different modification agents on hydrogen-generation by the reaction of $\mathrm{Al}$ with water. Int. J. Hydrogen Energy 2010, 35, 9561-9568. [CrossRef]

22. Deng, Z.-Y.; Ferreira, J.M.F.; Sakka, Y. Hydrogen-Generation Materials for Portable Applications. J. Am. Ceram. Soc. 2008, 91, 3825-3834. [CrossRef]

23. Dkhilalli, F.; Borchani, S.M.; Rasheed, M.; Barille, R.; Shihab, S.; Guidara, K.; Megdiche, M. Characterizations and morphology of sodium tungstate particles. R. Soc. Open Sci. 2018, 5, 172214. [CrossRef] [PubMed]

24. Yao, X.; Zhou, H.; Xu, K.; Xu, Q.; Li, L.; Haodong, Z. Investigation on the fusion characterization and melting kinetics of ashes from co-firing of anthracite and pine sawdust. Renew. Energy 2020, 145, 835-846. [CrossRef]

25. Yao, X.; Zhou, H.; Xu, K.; Chen, S.; Ge, J.; Xu, Q. Systematic study on ash transformation behaviour and thermal kinetic characteristics during co-firing of biomass with high ratios of bituminous coal. Renew. Energy 2020, 147, 1453-1468. [CrossRef]

26. Yao, X.; Zhou, H.; Xu, K.; Xu, Q.; Li, L. Evaluation of the fusion and agglomeration properties of ashes from combustion of biomass, coal and their mixtures and the effects of K2CO3 additives. Fuel 2019, 255, 115829. [CrossRef]

27. Yao, X.; Zheng, Y.; Zhou, H.; Xu, K.; Xu, Q.; Li, L. Effects of biomass blending, ashing temperature and potassium addition on ash sintering behaviour during co-firing of pine sawdust with a Chinese anthracite. Renew. Energy 2020, 147, 2309-2320. [CrossRef]

28. Hwang, I.J.; Shin, K.R.; Lee, J.S.; Ko, Y.G.; Shin, D.H. Formation of Black Ceramic Layer on Aluminum Alloy by Plasma Electrolytic Oxidation in Electrolyte Containing Na2WO4. Mater. Trans. 2012, 53, 559-564. [CrossRef]

29. Han, S.; Shin, W.S.; Seo, M.; Gupta, D.; Moon, S.-J.; Yoo, S. Improving performance of organic solar cells using amorphous tungsten oxides as an interfacial buffer layer on transparent anodes. Org. Electron. 2009, 10, 791-797. [CrossRef]

30. Dabkowski, A.; Dabbkowska, H.; Greedan, J.E.; Adachi, G.; Kobayashi, Y.; Tamura, S.; Hiaraiwa, M.; Imanaka, N. Crystal growth of aluminum tungstate Al2(WO4)3 by the Czochralski method from nonstoichiometric melt. J. Cryst. Growth 1999, 197, 879-882. [CrossRef]

31. Shpak, A.; Korduban, A.; Medvedskij, M.; Kandyba, V. XPS studies of active elements surface of gas sensors based on WO3-x nanoparticles. J. Electron Spectrosc. Relat. Phenom. 2007, 156, 172-175. [CrossRef]

32. Cai, Z.-X.; Li, H.-Y.; Yang, X.-N.; Guo, X. NO sensing by single crystalline WO3 nanowires. Sens. Actuators B Chem. 2015, 219, 346-353. [CrossRef]

33. Xie, F.; Gong, L.; Liu, X.; Tao, Y.; Zhang, W.; Chen, S.; Meng, H.; Chen, J. XPS studies on surface reduction of tungsten oxide nanowire film by Ar+ bombardment. J. Electron Spectrosc. Relat. Phenom. 2012, 185, 112-118. [CrossRef]

34. Gai, W.-Z.; Liu, W.-H.; Deng, Z.-Y.; Zhou, J.-G. Reaction of Al powder with water for hydrogen generation under ambient condition. Int. J. Hydrog. Energy 2012, 37, 13132-13140. [CrossRef]

35. Martínez-Salazar, A.; Melo-Banda, J.; Coronel-García, M.; González-Barbosa, J.; Domínguez-Esquivel, J. Hydrogen generation by aluminum alloy corrosion in aqueous acid solutions promoted by nanometal: Kinetics study. Renew. Energy 2020, 146, 2517-2523. [CrossRef]

36. Azizian, S.; Eris, S.; Wilson, L.D. Re-evaluation of the century-old Langmuir isotherm for modeling adsorption phenomena in solution. Chem. Phys. 2018, 513, 99-104. [CrossRef]

37. Helal, N.; Badawy, W.A. Environmentally safe corrosion inhibition of Mg-Al-Zn alloy in chloride free neutral solutions by amino acids. Electrochim. Acta 2011, 56, 6581-6587. [CrossRef]

(C) 2020 by the authors. Licensee MDPI, Basel, Switzerland. This article is an open access article distributed under the terms and conditions of the Creative Commons Attribution (CC BY) license (http://creativecommons.org/licenses/by/4.0/). 